\title{
Quempillén estuary, an experimental oyster cultivation station in southern Chile. Energy balance in Ostrea chilensis*
}

\author{
J. E. Winter, M. A. Acevedo and J. M. Navarro \\ Centro de Investigaciones Marinas, Universidad Austral de Chile, Casilla 567, Valdivia, Chile
}

\begin{abstract}
Rates of filtration, ingestion, assimilation, biodeposition, excretion and respiration of the Chilean flat oyster Ostrea chilensis Philippi were determined in laboratory experiments in order to establish energy budgets in relation to body size and 2 different food concentrations of the unicellular green alga Dunaliella marina. Ingestion and assimilation rates are kept constant within the range of food concentrations tested due to corresponding reductions in filtration activity with increasing food densities. The most favourable energy budget $\left(\mathrm{P}=a \mathrm{~W}^{b}\right)$ was obtained at the lowest food concentration tested $\left(0.54 \mathrm{mg}\right.$ algal dry wt $\left.1^{-1} ; 12^{\circ} \mathrm{C}, 20 \% \mathrm{~S}\right)$ with an a-value of 25.48 , when relating the energy disposable for growth and reproduction $\left(\mathrm{P}\right.$; cal $\left.\mathrm{d}^{-1}\right)$ to body size $(\mathrm{W}$; dry-tissue wt, $\mathrm{g})$. At the highest food concentration tested $\left(1.07 \mathrm{mg}^{-1}\right)$, the corresponding a-value of 17.38 was significantly lower. The relatively low scope for growth in $O$. chilensis is explained by a low species-specific filter-feeding activity and by the high energetic costs of routine metabolism which in a $1 \mathrm{~g}$ oyster (dry-tissue wt) vary between 58 and $62 \%$ of the energy ingested. The net growth efficiencies $\left(\mathrm{K}_{2}\right)$ decreased with increasing body size (from $50 \mathrm{mg}$ to $3000 \mathrm{mg}$ dry-tissue wt) from 53.7 to $22.6 \%$ at the lowest food level and from 51.1 to $13.9 \%$ at the highest food level tested. Comparison of estimated growth (calculated on the basis of the most favourable energy budget), with growth actually measured in oysters from natural banks and tray cultures, shows that the energy budgets established in the present study indeed reflect the conditions experienced by the oysters in their natural environment.
\end{abstract}

\section{INTRODUCTION}

Better understanding of the complex interactions of biotic and abiotic environmental variables regarding growth of oysters and a more detailed interpretation of growth data obtained in the field (Winter et al., 1983), can be achieved by laboratory experiments where experimental conditions are precisely defined and kept constant as much as possible.

For aquaculture it is of fundamental importance to know the optimal conditions for growth and reproduction, such as nutritive value and optimal densities of different unicellular algal food suspensions (Loosanoff and Engle, 1947; Davis and Guillard, 1958; Winter, 1969, 1973, 1976; Walne, 1970; Winter and Langton, 1976; Epifanio and Ewart, 1977; Helm, 1977; Langdon

\footnotetext{
- This research was supported by Grants RS-81-09 and C-80-1 of the D.I.D.-UACH, by CONICYT, Foundation Volkswagenwerk, Foundation Fritz-Thyssen, by the GTZ, and the Deutsche Forschungsgemeinschaft (DFG)
}

and Waldock, 1981; Navarro and Winter, 1982; Gerdes, 1983a; Toro and Winter, 1983a, b; Sprung, 1984a, b, c, d).

Aquaculture in estuarine systems, such as the estuary of the River Quempillén in the south of Chile (Chiloé Island), is highly influenced by great fluctuations in salinity and temperature (Widdows and Bayne, 1971; Dame, 1972; de Wilde, 1975; Widdows, 1978; Mann, 1979; Toro and Winter, 1983a; Sprung, 1984a, b, $c, d)$.

As pointed out by Mann (1978) and confirmed by observations made by the present authors, the natural occurrence of a species in a particular salinity-temperature regime does not necessarily indicate absence of environmental stress. The Chilean flat oyster Ostrea chilensis Philippi (1845) is in the estuarine waters of the River Quempillén under considerable stress, and part of an extensive aquaculture programme on bioenergetic estimations seeks to quantify that stress.

The laboratory experiments described in the present paper were designed to determine the different components of the energy budget of Ostrea chilensis in 


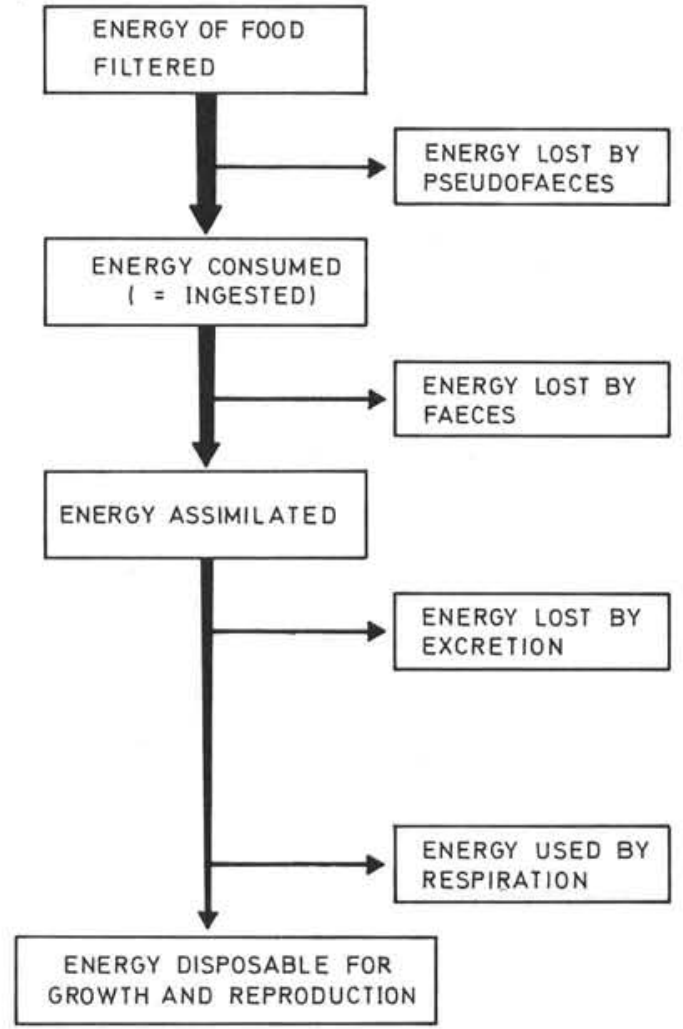

Fig. 1. Diagram of energy flow

relation to various algal food concentrations. They include studies on filtration, ingestion, assimilation, biodeposition, respiration and excretion rate and apply the same methods as used by Navarro and Winter (1982) for Mytilus chilensis in order to facilitate comparison between these 2 native bivalves from Chile (Fig. 1).

\section{MATERIAL AND METHODS}

Experimental oysters. Ostrea chilensis Philippi (1845) were collected from the natural bank in the estuary of the Quempillén River, southern Chile (Chiloé Island; Lat. $41^{\circ} 52^{\prime} \mathrm{S}$, Long. $73^{\circ} 46^{\prime} \mathrm{W}$ ). In this estuary, mean annual values for water temperature and salinity are $13.5^{\circ} \mathrm{C}$ and $23.6 \% \mathrm{~S}$, respectively, with monthly averages ranging from 8.8 to $18.9^{\circ} \mathrm{C}$ and from 13.0 to $29.9 \% \mathrm{~S}$.

For laboratory experiments, 5 size classes of oysters were selected ranging in shell length from 22.4 to $74.7 \mathrm{~mm}$. The oysters were maintained under laboratory conditions $\left(12^{\circ} \mathrm{C}, 20 \%\right.$ S) for $15 \mathrm{~d}$ before being used in the experiments. During this acclimatization period, seawater was changed every $3 \mathrm{~d}$, and the oysters were fed 5 times a day with Dunaliella marina Teodoresco. At the end of the experiments, relations between shell length and dry meat weight $(24 \mathrm{~h}$ at $\left.100^{\circ} \mathrm{C}\right)$, shell weight and displacement volume were determined (Fig. 2) in order to correlate these variables with the different physiological rates investigated (Fig. 1). Furthermore, the calorific content of the soft parts of the oysters was determined in relation to body size and season (Table 1). The average calorific content was $5361.34 \mathrm{cal} \mathrm{g}^{-1}$ dry-tissue weight.

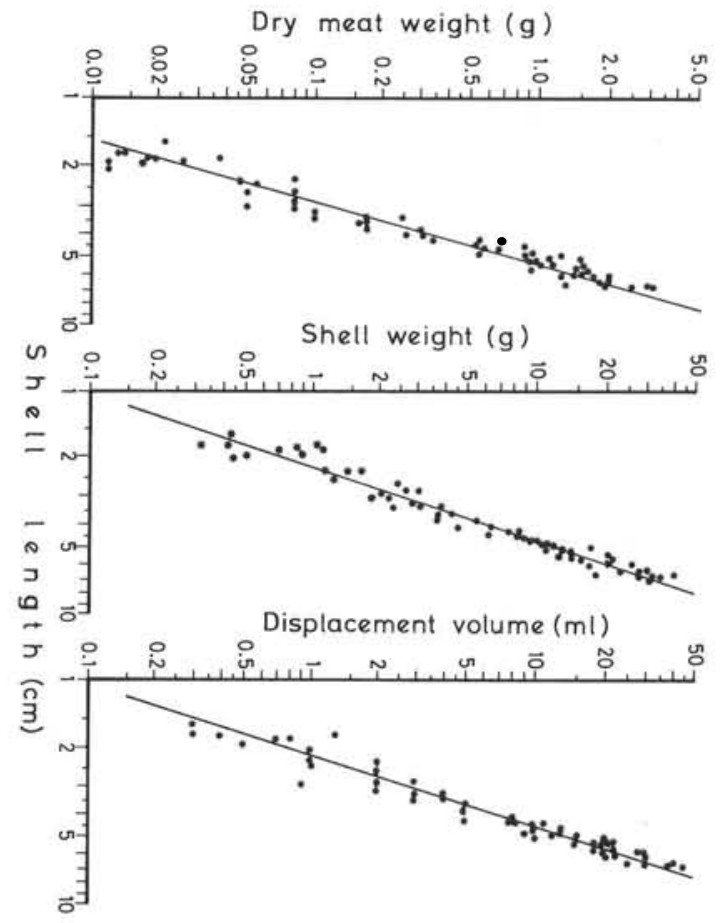

Fig. 2. Ostrea chilensis. Relations between shell length, dry meat weight, shell weight, and displacement volume of oysters collected during August (estuary of the Quempillén River in the north of Chiloé Island, southern Chile). Correlation coefficient $(\mathrm{r})$ for each relation is the same: 0.98

Table 1. Ostrea chilensis. Seasonal variations in calorific content of dry-tissues in relation to body size. The 2 values for each size class and season correspond directly to the range of dry-tissue weight indicated for each size class

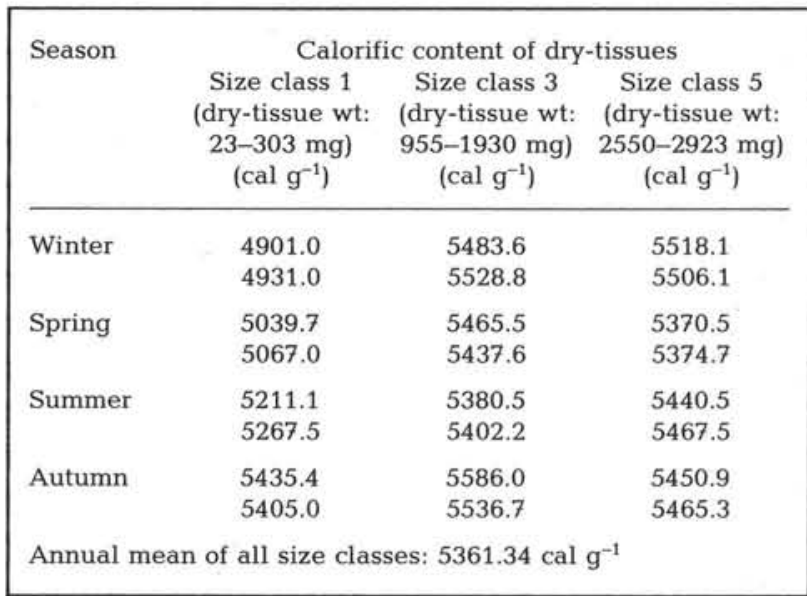



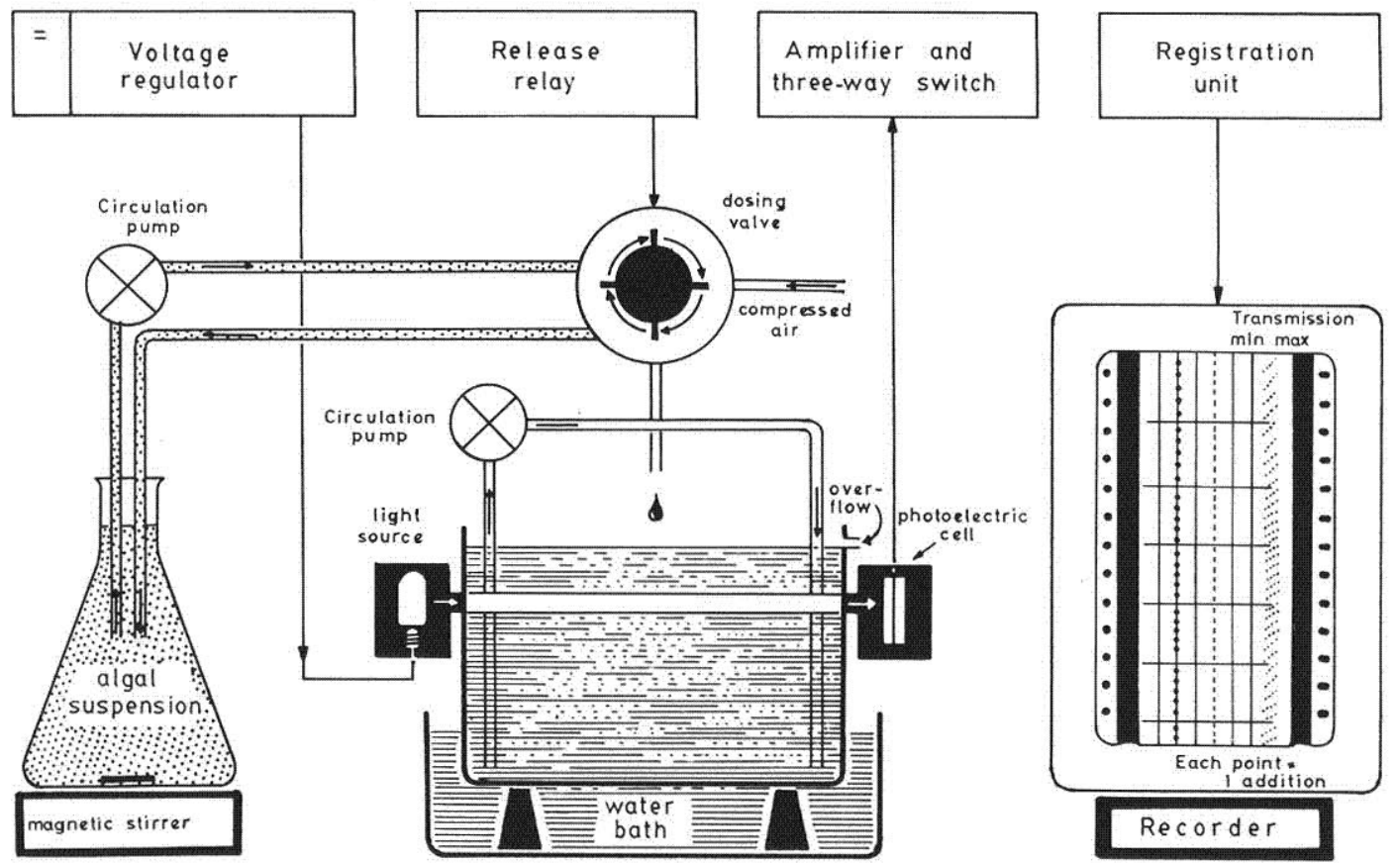

Fig. 3. Apparatus for measuring filtration rates (after Winter, 1973)

Algal suspension. Oysters were fed pure cultures of Dunaliella marina $(5.0 \times 7.5 \mu \mathrm{m})$ cultured as described by Winter (1969) and used only as food during logarithmic growth. Average calorific content of $D$. marina was $4618 \mathrm{cal} \mathrm{g}^{-1}$ dry weight and $4975 \mathrm{cal} \mathrm{g}^{-1}$ ash-free dry weight.

Filtration rate. Filtration rate was determined by an indirect method quantifying the decrease in algal cell density of the experimental medium in relation to time, using the automatic recording apparatus described by Winter $(1973,1978 a)$. A homogeneous mixture of the experimental medium was ensured by a circulation pump (Fig. 3) with a capacity of $31 \mathrm{~min}^{-1}$. The oysters were arranged in the photo-aquaria of the apparatus in such a way as to avoid disturbance due to currents produced by their inhalant and exhalant apertures. Such special care and the relatively high capacity of the circulation pump are necessary in order to avoid refiltering of the exhalant water before being readjusted to the cell concentration of the experimental medium.

Experiments were carried out over $24 \mathrm{~h}$ in $16 \mathrm{l}$ of seawater $\left(20 \% \mathrm{~S}, 12^{\circ} \mathrm{C}\right)$. Filtration rate was determined at algal concentrations of $10 \times 10^{6}$ and $20 \times 10^{6}$ Dunaliella marina cells $1^{-1}$, corresponding to 0.54 and $1.07 \mathrm{mg}$ dry weight $\mathrm{l}^{-1}$, respectively.

Assimilation efficiency was determined according to Conover (1966). Faeces were collected, washed and dried immediately at the end of each filtration-rate experiment in order to avoid decomposition.
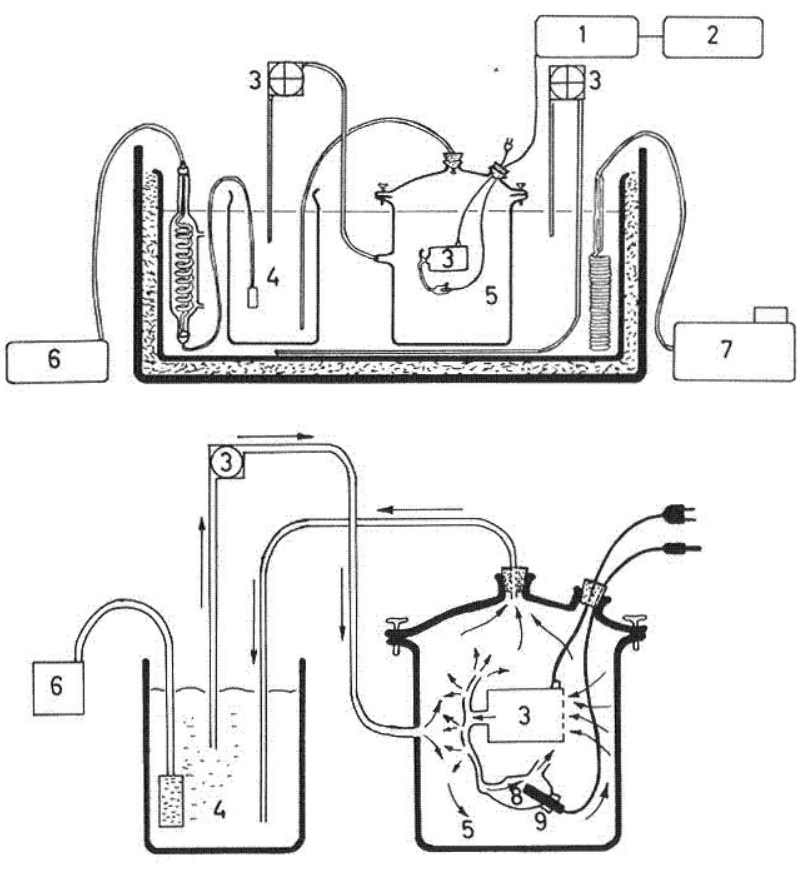

1 Amplifier and oxygen meter

2 Recorder

6 Aeration system

3 Circulation pump

7 Cooling system

4 Saturation chamber

8 Electrode chamber

5 Respiration chamber

9 Oxygen electrode

Fig. 4. Apparatus used for measuring oxygen consumption. For further explanation see text 
Excretion rate. To determine excretion rate in relation to body size, well-fed oysters were incubated in 1 to $4 \mathrm{l}$ of seawater for $5 \mathrm{~h}$. Controls of filtered seawater from the same batch, but without oysters, were incubated at the same time. Samples and controls were analysed according to Solórzano (1969) and expressed as $\mu \mathrm{g}$ ammonia-nitrogen oyster ${ }^{-1} \mathrm{~h}^{-1}$. The results obtained were transformed to calories $\left(1 \mathrm{mg} \mathrm{NH} \mathrm{NH}_{4}-\mathrm{N}=5.94 \mathrm{cal}\right)$ using the coefficient given by Elliot and Davison (1975).

Respiration rate was measured in the apparatus (Fig. 4) previously described by Ríos (1979). The apparatus consists, in addition to the oxygen meter unit with the electrode, of a saturation and a respiration chamber connected with each other during saturation before each experiment and disconnected during the subsequent oxygen consumption determination (closed system).

Respiration rate was determined in relation to body size under 3 different physiological conditions: (a) in starved oysters ( $3 \mathrm{~d}$ without food; filtered seawater); (b) in well-fed oysters (subsequent to each filtration rate experiment); (c) in feeding oysters. In the last case, experimental food concentrations were kept constant by injections of concentrated algal culture into the water of the respiration chamber. All these measurements were carried out at $12{ }^{\circ} \mathrm{C}$ and $20 \%$ S. Values for oxygen consumption were expressed in $\mathrm{ml} \mathrm{O}_{2} \mathrm{~h}^{-1}$ and transformed to calories using the coefficient given by Thompson and Bayne (1974) $\left(1 \mathrm{ml} \mathrm{O}_{2}=4.75 \mathrm{cal}\right)$.

\section{RESULTS}

The results are presented in a chronological sequence according to the energy flow diagram given in Fig. 1.

\section{Filtration rate}

The filtration rate of suspension-feeding organisms is of great ecological importance. It is defined as the volume of water filtered completely free of particles per unit of time, whereas the pumping or ventilation rate refers to the water volume flowing through the gills per unit time. Filtration rate and pumping rate have the same numerical value only if all particles entering the mantle cavity are completely $(100 \%)$ retained by the gills (Winter, 1978a).

Relations between filtration rate and body size were determined in 5 different size classes of Ostrea chilensis at 2 different algal densities $\left(10 \times 10^{6}\right.$ and $20 \times 10^{6}$ Dunaliella marina cells $1^{-1}$ ) corresponding to a total algal dry weight of $0.54 \mathrm{mg}$ and $1.07 \mathrm{mg} \mathrm{l}^{-1}$, respectively.

Results are expressed by the following regression equations $\left(\mathrm{Fr}=a W^{b}\right)$ relating filtration rate $\left(\mathrm{FR}_{i} l \mathrm{~h}^{-1}\right)$ to body size (drey-tissue weight, $\mathrm{W} ; \mathrm{g}$ ) at the 2 different food concentrations tested:

$$
\begin{aligned}
& 10 \times 10^{6} \text { cells } 1^{-1}: \mathrm{FR}=1.32 \mathrm{~W}^{0.63} \text {, } \\
& 20 \times 10^{6} \text { cells } 1^{-1}: \mathrm{FR}=0.62 \mathrm{~W}^{0.60} \text {. }
\end{aligned}
$$

From these equations and from Fig. 5 it is clear that the filtration rate increases with increasing body size. Furthermore, it is obvious that an increase in food concentration results in a pronounced reduction in

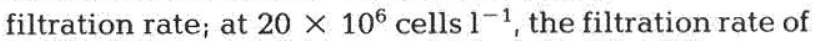
a 1 -g oyster (dry-tissue weight) is reduced by $53 \%$ when compared with the filtration rate at the low food concentration of $10 \times 10^{6}$ cells $1^{-1}$.

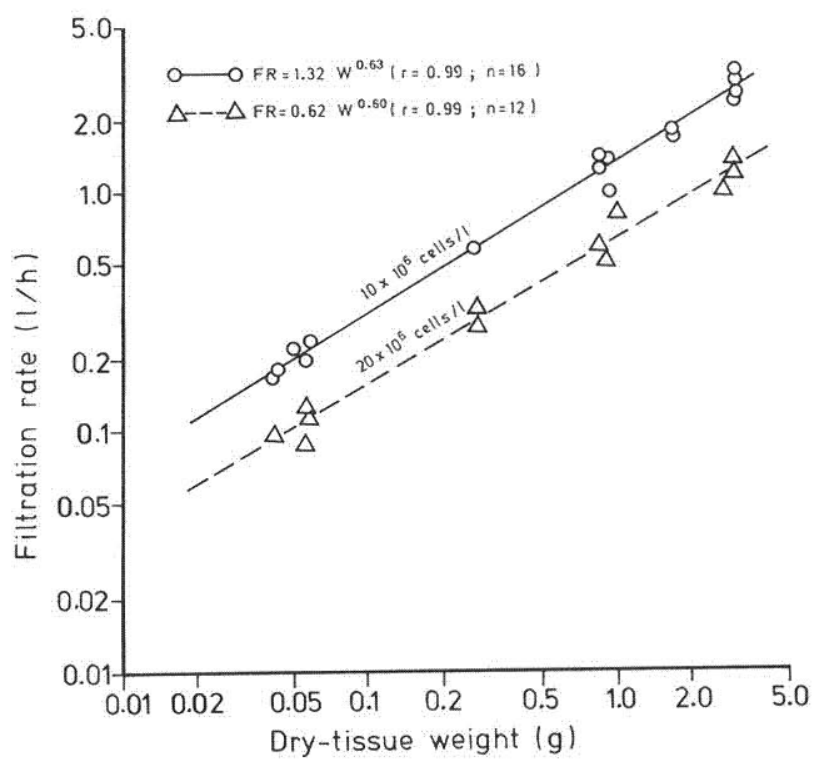

Fig. 5. Ostrea chilensis. Filtration rate at $12{ }^{\circ} \mathrm{C}$ and $20 \% \mathrm{~S}$ in relation to body size at 2 different concentrations of Dunaliella marina

\section{Ingestion rate}

Knowing filtration rate and concentration of suspended particles in the water (food concentration), it is possible to calculate the amount of food retained by the gills and ingested by the oyster, as long as no pseudofaeces are produced. In our experiments the amount of algae ingested is identical with the amount of algae filtered-out, since production of pseudofaeces could not be detected at the algal densities tested.

Ingestion rate (IR; $\mathrm{mg}$ algal dry weight $\mathrm{d}^{-1}$ ) is directly influenced by the regulation of filtration rate in relation to food concentration; this is reflected by the equations:

$$
\begin{aligned}
& 10 \times 10^{6} \text { cells } 1^{-1}: I R=17.11 \mathrm{~W}^{0.63}, \\
& 20 \times 10^{6} \text { cells } 1^{-1}: \mathrm{IR}=15.92 \mathrm{~W}^{0.60} .
\end{aligned}
$$

These equations reveal that the ingestion rate of a 
1-g oyster (dry-tissue weight) is nearly independent of the range of food concentrations tested; this is explained as being the result of a high reduction in filtration rate at the higher cell density. The slightly lower $a$-value at $20 \times 10^{6}$ cells $1^{-1}$ suggests that a further increase in food concentration will have a negative effect on food intake. From the very similar $b$-values it is deduced that the relative increase in filtration rate and/or ingestion rate in relation to body size is independent of food concentration, i.e. large as well as small oysters react in the same manner towards different algal concentrations.

The daily amount of food ingested (total algal dry weight), expressed as percentage of body weight (drytissue weight; Table 2), may be used as an ecologically relevant index of feeding activity. In Fig. 6, this index is plotted against body size (dry-tissue weight); the graph shows that the index decreases rapidly with increasing body size. This means that the relative amount of food ingested is much higher in smaller than in larger oysters. Thus, the daily ration of food ingested by small oysters (40 mg dry-tissue weight; Table 2) amounts to about $5.5 \%$ of their dry-tissue weight, while large oysters $(3,097 \mathrm{mg})$ only ingest about $1 \%$ of their dry-tissue weight per day. The small differences of this relation at the 2 different food concentrations tested can be deduced from the following equations:

$$
\begin{aligned}
& 10 \times 10^{6}{\text { cells } 1^{-1}: \mathrm{IR}_{\%}}^{10}=1.71 \mathrm{~W}^{-0.38}, \\
& 20 \times 10^{6} \text { cells } \mathrm{I}^{-1}: \mathrm{IR}_{\%}=1.60 \mathrm{~W}^{-0.40} .
\end{aligned}
$$

As assimilation efficiency determined according to Conover (1966) refers only to the degree of utilization of the organic material ingested, it is necessary to calculate the following equations for the organic material ingested $\left(\mathrm{IR}_{\text {ori }} \mathrm{mg}\right.$ organic algal dry weight $\left.\mathrm{d}^{-1}\right)$ in relation to body size:

$$
\begin{aligned}
& 10 \times 10^{6} \text { cells } 1^{-1}: \mathrm{IR}_{\text {or }}=16.13 \mathrm{~W}^{0.63}, \\
& 20 \times 10^{6} \text { cells } \mathrm{I}^{-1}: \mathrm{IR}_{\text {or }}=15.01 \mathrm{~W}^{0.60} .
\end{aligned}
$$

\begin{tabular}{|c|c|c|c|c|c|}
\hline \multicolumn{2}{|c|}{ Body size } & \multicolumn{2}{|c|}{ Filtration rate } & \multirow{2}{*}{\multicolumn{2}{|c|}{$\begin{array}{l}\text { Ingestion rate } d^{-1} \\
\text { (algal dry wt) }\end{array}$}} \\
\hline Shell & Dry-tissue & per & per mg & & \\
\hline$(\mathrm{mm})$ & $(\mathrm{mg})$ & $\begin{array}{l}\text { oyster } \\
\left(\mathrm{ml} \mathrm{h}^{-1}\right)\end{array}$ & $\begin{array}{l}\text { dry-tissue } \\
\text { weight } \\
\left(\mathrm{ml} \mathrm{h}^{-1}\right)\end{array}$ & $\begin{array}{c}\text { per } \\
\text { oyster } \\
\left(\mathrm{mg} \mathrm{d}^{-1}\right)\end{array}$ & $\begin{array}{c}\text { relative to } \\
\text { dry-tissue } \\
\text { weight } \\
(\%)\end{array}$ \\
\hline \multicolumn{6}{|c|}{ Food concentration: $10 \times 10^{6}$ cells $1^{-1}$} \\
\hline 22.4 & 40 & 169 & 4.2 & 2.19 & 5.48 \\
\hline 22.7 & 42 & 178 & 4.2 & 2.31 & 5.50 \\
\hline 23.6 & 49 & 218 & 4.4 & 2.83 & 5.78 \\
\hline 24.4 & 55 & 198 & 3.6 & 2.57 & 4.67 \\
\hline 24.8 & 58 & 235 & 4.1 & 3.05 & 5.26 \\
\hline 37.6 & 262 & 569 & 2.2 & 7.37 & 2.81 \\
\hline 52.1 & 852 & 1380 & 1.6 & 17.88 & 2.10 \\
\hline 52.1 & 852 & 1238 & 1.5 & 16.04 & 1.88 \\
\hline 53.2 & 918 & 988 & 1.1 & 12.80 & 1.39 \\
\hline 53.3 & 925 & 1350 & 1.5 & 17.50 & 1.89 \\
\hline 62.7 & 1662 & 1780 & 1.1 & 23.07 & 1.39 \\
\hline 63.2 & 1710 & 1692 & 1.0 & 21.93 & 1.28 \\
\hline 73.9 & 3008 & 3112 & 1.0 & 40.33 & 1.34 \\
\hline 74.0 & 3022 & 2841 & 0.9 & 36.82 & 1.22 \\
\hline 74.5 & 3097 & 2360 & 0.8 & 30.59 & 0.99 \\
\hline 74.7 & 3127 & 2537 & 0.8 & 32.88 & 1.05 \\
\hline \multicolumn{6}{|c|}{ Food concentration: $20 \times 10^{6}$ cells $\mathrm{I}^{-1}$} \\
\hline 22.5 & 41 & 96 & 2.3 & 2.47 & 6.02 \\
\hline 24.4 & 55 & 125 & 2.3 & 3.21 & 5.84 \\
\hline 24.4 & 55 & 88 & 1.6 & 2.26 & 4.11 \\
\hline 24.6 & 57 & 116 & 2.0 & 2.98 & 5.23 \\
\hline 37.9 & 270 & 320 & 1.2 & 8.22 & 3.04 \\
\hline 37.8 & 267 & 273 & 1.0 & 7.01 & 2.63 \\
\hline 52.8 & 894 & 510 & 0.6 & 13.10 & 1.47 \\
\hline 51.9 & 840 & 580 & 0.7 & 14.89 & 1.77 \\
\hline 54.3 & 989 & 710 & 0.7 & 18.23 & 1.84 \\
\hline 71.7 & 2697 & 990 & 0.4 & 25.42 & 0.94 \\
\hline 73.5 & 2949 & 1342 & 0.5 & 34.46 & 1.17 \\
\hline 73.7 & 2978 & 1152 & 0.4 & 29.58 & 0.99 \\
\hline
\end{tabular}

Table 2. Ostrea chilensis. Filtration and ingestion rate in relation to body size at 2 different algal concentrations (Dunaliella marina; $12{ }^{\circ} \mathrm{C} ; 20 \% \mathrm{~S}$ ) 


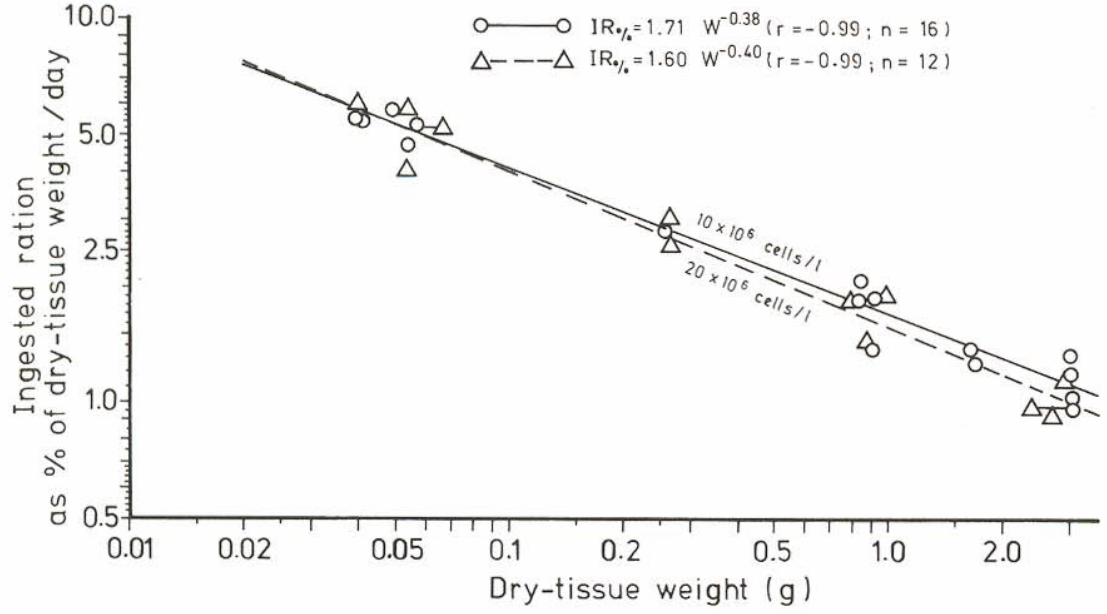

Fig. 6. Ostrea chilensis. Relations between ingested ration $\mathrm{d}^{-1}$ (expressed as percentage of dry-tissue weight) and body size (dry-tissue weight) at 2 different concentrations of Dunaliella marina

\section{Assimilation efficiency}

The amount of organic material assimilated, expressed as percentage of the amount of organic material ingested, is defined as assimilation efficiency. Assimilation efficiency depends, above all, on the quality and quantity of the food ingested. Assimilation efficiency (AE) was determined in relation to body size (drytissue weight; g) at the 2 different food concentrations investigated (Fig. 7). The results obtained are summarized in the following equations:

$$
\begin{aligned}
& 10 \times 10^{6} \text { cells } \mathrm{l}^{-1}: \mathrm{AE}=92.88 \mathrm{~W}^{-0.019} \\
& 20 \times 10^{6} \text { cells }^{-1}: \mathrm{AE}=88.98 \mathrm{~W}^{-0.008} .
\end{aligned}
$$

These equations indicate that assimilation efficiency is, to a high degree, independent of body size ( $b$-values very close to zero) at the 2 food concentrations tested. Furthermore, assimilation efficiency (a-values) in oysters fed Dunaliella marina is very high, about $90 \%$, and within the range of food concentrations tested practically independent of cell density.

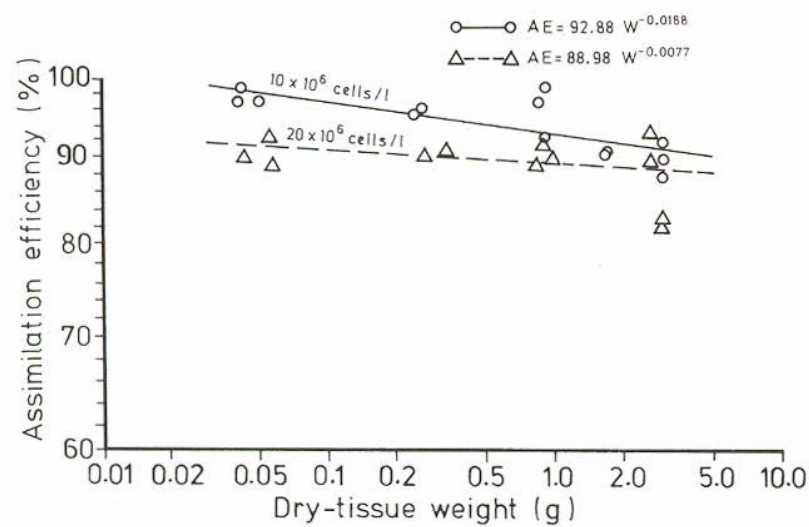

Fig. 7. Ostrea chilensis. Assimilation efficiency in relation to body size (dry-tissue weight) at 2 different concentrations of Dunaliella marina

\section{Assimilation rate}

Assimilation rate $\left(\mathrm{AR}_{i} \mathrm{mg}\right.$ organic algal dry weight $\mathrm{d}^{-1}$ ) in relation to body size and food concentration was calculated on the basis of data obtained for ingestion rate (organic material) and assimilation efficiency. The relations are described by the following equations:

$$
\begin{aligned}
& 10 \times 10^{6} \text { cells } \mathrm{l}^{-1}: \mathrm{AR}=14.98 \mathrm{~W}^{0.61} \\
& 20 \times 10^{6} \text { cells } \mathrm{I}^{-1}: \mathrm{AR}=13.36 \mathrm{~W}^{0.59} .
\end{aligned}
$$

Analysis of the $a$-values of these equations reveals that assimilation rate is nearly independent of the food concentrations employed. This independence is due to effective regulation of the filtration and/or ingestion rate.

When comparing the $b$-values of these equations with those found for the filtration and ingestion rate, it becomes clear that all these physiological rates follow the same pattern of body-size dependence.

\section{Biodeposition rate}

Biodeposition of organic material in relation to body size was calculated as the difference between organic material ingested $\left(\mathrm{IR}_{\mathrm{or}}\right)$ and organic material assimilated (AR). Biodeposition rate $\left(\mathrm{BR}_{\text {ori }} \mathrm{mg}\right.$ organic faecal dry weight $\mathrm{d}^{-1}$ ) is expressed by:

$$
\begin{aligned}
& 10 \times 10^{6} \text { cells } \mathrm{l}^{-1}: \mathrm{BR}_{\text {or }}=1.15 \mathrm{~W}^{1.03}, \\
& 20 \times 10^{6} \text { cells } \mathrm{l}^{-1}: \mathrm{BR}_{\text {or }}=1.65 \mathrm{~W}^{0.67} .
\end{aligned}
$$

The $a$ - and $b$-values of these equations are clearly dependent on the food concentrations tested. This is in contrast to the ingestion and assimilation rates which are practically independent of food concentration. These findings are interpreted later; it should be pointed out here that the assimilation efficiency is very 
high in oysters fed Dunaliella marina (about $90 \%$ ) and that the biodeposition rate is based on the remaining $10 \%$ of the organic material ingested but not assimilated.

\section{Excretion rate}

Further metabolic loss occurs due to excretion. Data for excretion rates in well-fed oysters $\left(\mathrm{ER}_{i} \mu \mathrm{g} \mathrm{NH}_{4^{-}}\right.$ $\mathrm{N} \mathrm{h}^{-1}$ ) are summarized in Table 3 and plotted against body size (dry-tissue weight) in Fig. 8 . The relation obtained is expressed by:

$$
\mathrm{ER}=16.25 \mathrm{~W}^{0.56} .
$$

Table 3. Ostrea chilensis. Excretion rate of ammonia-nitrogen $\left(\mu \mathrm{g} \mathrm{NH} \mathrm{NH}_{4}-\mathrm{N} / \mathrm{h}\right)$ in relation to body size $\left(12^{\circ} \mathrm{C}_{i} 20 \% \mathrm{~S}\right)$

\begin{tabular}{|ccccc|}
$\begin{array}{c}\text { Experi- } \\
\text { ment } \\
\text { no. }\end{array}$ & $\begin{array}{c}\text { Number } \\
\text { of } \\
\text { oysters }\end{array}$ & $\begin{array}{c}\text { Body size (means) } \\
\text { Shell } \\
\text { length } \\
(\mathrm{mm})\end{array}$ & $\begin{array}{c}\text { Dry-tissue } \\
\text { weight } \\
(\mathrm{mg})\end{array}$ & $\begin{array}{c}\text { Excretion } \\
\text { rate } \\
\left(\mathrm{NH}_{4}-\mathrm{N}\right) \\
\left(\mu \mathrm{g} \mathrm{h}^{-1}\right)\end{array}$ \\
\hline 1 & 30 & 23.4 & 47 & 3.55 \\
2 & 30 & 22.9 & 44 & 2.68 \\
3 & 40 & 23.1 & 45 & 3.40 \\
4 & 40 & 23.1 & 45 & 3.51 \\
5 & 40 & 23.1 & 45 & 2.99 \\
6 & 37 & 22.3 & 40 & 2.87 \\
7 & 37 & 22.3 & 40 & 2.24 \\
8 & 8 & 52.1 & 852 & 12.84 \\
9 & 8 & 52.1 & 852 & 11.12 \\
10 & 8 & 52.8 & 894 & 11.37 \\
11 & 8 & 52.8 & 894 & 10.69 \\
12 & 8 & 53.6 & 943 & 11.97 \\
13 & 8 & 53.6 & 943 & 13.14 \\
14 & 8 & 53.6 & 943 & 13.55 \\
15 & 5 & 70.2 & 2499 & 39.56 \\
16 & 5 & 70.2 & 2499 & 42.27 \\
17 & 3 & 70.2 & 2499 & 30.16 \\
18 & 3 & 70.2 & 2499 & 37.49 \\
& & & & \\
\hline
\end{tabular}

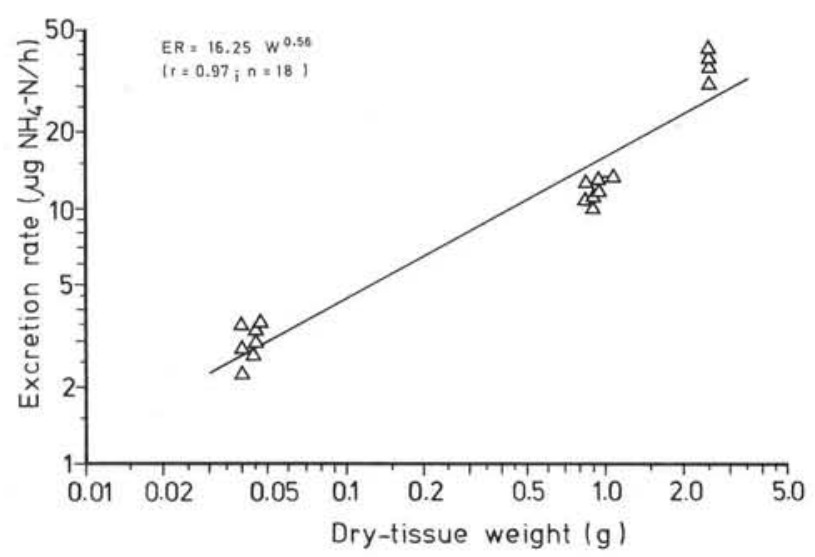

Fig. 8. Ostrea chilensis. Relation between excretion rate and body size (dry-tissue weight) in well-fed oysters $\left(12^{\circ} \mathrm{C}\right.$, $20 \%$ S)

\section{Respiration rate}

Respiration rates $\left(\mathrm{RR}_{;} \mathrm{ml} \mathrm{O}_{2} \mathrm{~h}^{-1}\right)$, obtained under the 3 different experimental conditions, are shown in Fig. 9 and summarized by:

$$
\begin{array}{ll}
\text { starved oysters: } & \mathrm{RR}=0.266 \mathrm{~W}^{0.75}, \\
\text { well-fed oysters: } & \mathrm{RR}=0.377 \mathrm{~W}^{0.73}, \\
\text { feeding oysters: } & \mathrm{RR}=0.410 \mathrm{~W}^{0.74} .
\end{array}
$$

Oxygen consumption determined in starved oysters corresponds to the energetic costs of standard metabolism. The significant increase in oxygen consumption (compare $a$-values) of well-fed oysters expresses the physiological costs due to digestion; the further small increase in oxygen consumption in feeding oysters (routine metabolism) is principally due to filter-feeding (mechanical costs).

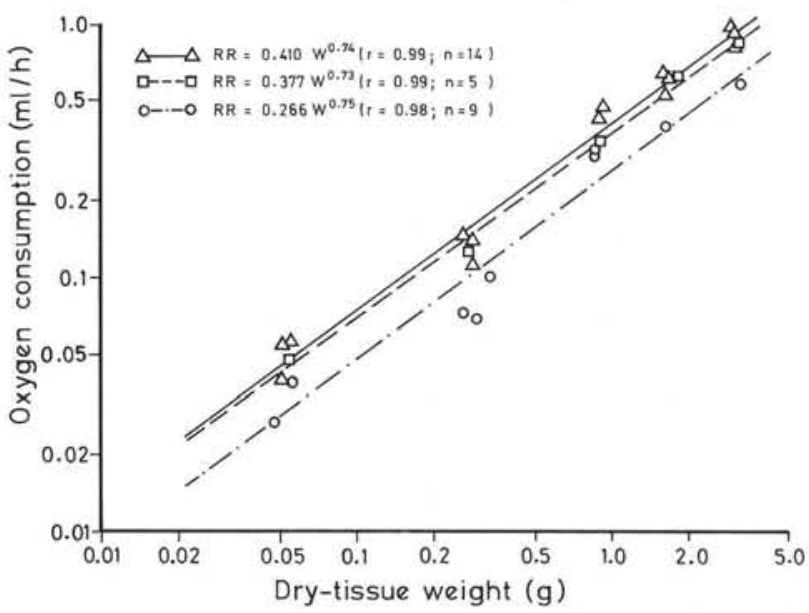

Fig. 9. Ostrea chilensis. Oxygen consumption in relation to body size (dry-tissue weight) under 3 different experimental conditions: starved oysters (broken/dotted line; circles), wellfed oysters (broken line; squares), feeding oysters (solid line; triangles)

Energetic costs are listed in Table 4 ; they are expressed as percentages of the costs of routine metabolism $(=100 \%)$. Table 4 shows that the costs for standard metabolism increase from 62.9 to $65.6 \%$, those for mechanical efforts (filter-feeding) from 5.3 to $9.0 \%$ with increasing body size; the physiological costs for digestion decrease from $31.8 \%$ in small oysters $(50 \mathrm{mg}$ dry-tissue weight) to $25.4 \%$ in large ones $(3,000 \mathrm{mg})$.

\section{Energy balance}

In order to calculate the energy balance in Ostrea chilensis it is necessary to transform the different physiological rates, quantified and summarized in Table 5 , to units of energy (calories). These transformations are shown in Table 6 for the different physiological rates 
Table 4. Ostrea chilensis. Oxygen consumption $\left(12{ }^{\circ} \mathrm{C} ; 20 \% \mathrm{~S}\right)$ in relation to body size and different metabolic conditions (Values calculated from regression equations)

\begin{tabular}{|c|c|c|c|c|c|c|c|c|c|c|c|}
\hline \multicolumn{2}{|c|}{ Body size } & \multicolumn{3}{|c|}{ Oxygen consumption } & \multicolumn{7}{|c|}{ Energy consumption (routine metabolism $=100 \%$ ) } \\
\hline $\begin{array}{c}\text { Dry } \\
\text { tissue }\end{array}$ & $\begin{array}{c}\text { Shell } \\
\text { length }\end{array}$ & $\begin{array}{l}\text { Stand. } \\
\text { metabol. }\end{array}$ & $\begin{array}{l}\text { Stand. } \\
\text { metabol. }\end{array}$ & $\begin{array}{l}\text { Stand. } \\
\text { metabol. }\end{array}$ & Stand. $\mathrm{m}$ & tabol. & Feed & & Dige & ion & $\begin{array}{l}\text { Routine } \\
\text { metabol. }\end{array}$ \\
\hline (mg) & $(\mathrm{mm})$ & $\left(\mathrm{ml} \mathrm{h}^{-1}\right)$ & $\left(\mathrm{ml} \mathrm{h}^{-1}\right)$ & $\left(\mathrm{ml} \mathrm{h}^{-1}\right)$ & $\left(\mathrm{cal} \mathrm{h}^{-1}\right)$ & $(\%)$ & $\left(\mathrm{cal} \mathrm{h}^{-1}\right)$ & $(\%)$ & $\left(\mathrm{cal} \mathrm{h}^{-1}\right)$ & $(\%)$ & $\left(\mathrm{cal} \mathrm{h}^{-1}\right)$ \\
\hline 50 & 23.7 & 0.028 & 0.042 & 0.045 & 0.134 & 62.9 & 0.011 & 5.3 & 0.067 & 31.8 & 0.212 \\
\hline 250 & 37.1 & 0.094 & 0.137 & 0.147 & 0.446 & 63.9 & 0.048 & 6.8 & 0.204 & 29.3 & 0.698 \\
\hline 500 & 44.9 & 0.158 & 0.227 & 0.246 & 0.752 & 64.4 & 0.086 & 7.4 & 0.328 & 28.2 & 1.166 \\
\hline 1000 & 54.4 & 0.266 & 0.377 & 0.410 & 1.264 & 64.9 & 0.157 & 8.0 & 0.527 & 27.1 & 1.948 \\
\hline 1500 & 60.9 & 0.361 & 0.507 & 0.554 & 1.712 & 65.1 & 0.221 & 8.4 & 0.696 & 26.5 & 2.629 \\
\hline 2000 & 66.0 & 0.447 & 0.625 & 0.685 & 2.125 & 65.3 & 0.283 & 8.7 & 0.845 & 26.0 & 3.253 \\
\hline 2500 & 70.2 & 0.529 & 0.736 & 0.808 & 2.512 & 65.5 & 0.341 & 8.9 & 0.983 & 25.6 & 3.836 \\
\hline 3000 & 73.8 & 0.606 & 0.841 & 0.924 & 2.880 & 65.6 & 0.398 & 9.0 & 1.113 & 25.4 & 4.391 \\
\hline
\end{tabular}

Table 5. Ostrea chilensis. Rates of filtration, ingestion, assimilation, biodeposition, respiration and excretion in relation to body size and 2 different algal concentrations $\left(12{ }^{\circ} \mathrm{C}_{i} 20 \% \mathrm{~S}\right)$

\begin{tabular}{|c|c|c|c|c|c|c|c|c|c|c|}
\hline $\begin{array}{l}\text { Body } \\
\text { Dry } \\
\text { tissue } \\
\text { weight } \\
\text { (mg) }\end{array}$ & $\begin{array}{l}\text { Shell } \\
\text { length } \\
\text { (mm) }\end{array}$ & $\begin{array}{l}\text { Algal } \\
\text { density }\end{array}$ & $\begin{array}{l}\text { Filtra- } \\
\text { tion } \\
\text { rate }\end{array}$ & $\begin{array}{l}\text { Inge } \\
\text { Total } \\
\text { algal } \\
\text { dry wt } \\
\left(\mathrm{mg} \mathrm{d}^{-1}\right)\end{array}$ & $\begin{array}{l}\text { ion rate } \\
\text { Organic } \\
\text { algal } \\
\text { dry wt } \\
\left(\mathrm{mg} \mathrm{d}^{-1}\right)\end{array}$ & $\begin{array}{l}\text { As } \\
\text { effi- } \\
\text { ciency } \\
(\%)\end{array}$ & $\begin{array}{l}\text { ilation } \\
\text { rate } \\
\left(\mathrm{mg} \mathrm{d}^{-1}\right)\end{array}$ & $\begin{array}{l}\text { Biode- } \\
\text { position } \\
\text { rate } \\
\left(\mathrm{mg} \mathrm{d}^{-1}\right)\end{array}$ & $\begin{array}{l}\text { Respi- } \\
\text { ration } \\
\text { rate } \\
\left(\mathrm{ml} \mathrm{d}^{-1}\right)\end{array}$ & $\begin{array}{l}\text { Excre- } \\
\text { cretion } \\
\text { rate } \\
\left(\mu \mathrm{g} \mathrm{d}^{-1}\right)\end{array}$ \\
\hline 50 & 23.7 & $\begin{array}{l}10 \\
20\end{array}$ & $\begin{array}{l}4.799 \\
2.466\end{array}$ & $\begin{array}{l}2.59 \\
2.64\end{array}$ & $\begin{array}{l}2.44 \\
2.49\end{array}$ & $\begin{array}{l}98.26 \\
91.06\end{array}$ & $\begin{array}{l}2.40 \\
2.27\end{array}$ & $\begin{array}{l}0.04 \\
0.22\end{array}$ & 1.07 & 72.9 \\
\hline 250 & 37.1 & $\begin{array}{l}10 \\
20\end{array}$ & $\begin{array}{r}13.228 \\
6.477\end{array}$ & $\begin{array}{l}7.14 \\
6.93\end{array}$ & $\begin{array}{l}6.73 \\
6.53\end{array}$ & $\begin{array}{l}95.33 \\
89.93\end{array}$ & $\begin{array}{l}6.42 \\
5.87\end{array}$ & $\begin{array}{l}0.31 \\
0.66\end{array}$ & 3.53 & 179.4 \\
\hline 500 & 44.9 & $\begin{array}{l}10 \\
20\end{array}$ & $\begin{array}{r}20.471 \\
9.817\end{array}$ & $\begin{array}{l}11.05 \\
10.50\end{array}$ & $\begin{array}{c}10.42 \\
9.90\end{array}$ & $\begin{array}{l}94.10 \\
89.46\end{array}$ & $\begin{array}{l}9.81 \\
8.86\end{array}$ & $\begin{array}{l}0.61 \\
1.04\end{array}$ & 5.89 & 264.5 \\
\hline 1000 & 54.4 & $\begin{array}{l}10 \\
20\end{array}$ & $\begin{array}{l}31.680 \\
14.880\end{array}$ & $\begin{array}{l}17.11 \\
15.92\end{array}$ & $\begin{array}{l}16.13 \\
15.01\end{array}$ & $\begin{array}{l}92.88 \\
88.98\end{array}$ & $\begin{array}{l}14.98 \\
13.36\end{array}$ & $\begin{array}{l}1.15 \\
1.65\end{array}$ & 9.84 & 390.0 \\
\hline 1500 & 60.9 & $\begin{array}{l}10 \\
20\end{array}$ & $\begin{array}{l}40.900 \\
18.978\end{array}$ & $\begin{array}{l}22.09 \\
20.31\end{array}$ & $\begin{array}{l}20.82 \\
19.15\end{array}$ & $\begin{array}{l}92.17 \\
88.70\end{array}$ & $\begin{array}{l}19.19 \\
16.99\end{array}$ & $\begin{array}{l}1.63 \\
2.16\end{array}$ & 13.28 & 489.4 \\
\hline 2000 & 66.0 & $\begin{array}{l}10 \\
20\end{array}$ & $\begin{array}{l}49.027 \\
22.554\end{array}$ & $\begin{array}{l}26.47 \\
24.13\end{array}$ & $\begin{array}{l}24.95 \\
22.75\end{array}$ & $\begin{array}{l}91.68 \\
88.51\end{array}$ & $\begin{array}{l}22.87 \\
20.14\end{array}$ & $\begin{array}{l}2.08 \\
2.61\end{array}$ & 16.44 & 575.0 \\
\hline 2500 & 70.2 & $\begin{array}{l}10 \\
20\end{array}$ & $\begin{array}{l}56.427 \\
25.785\end{array}$ & $\begin{array}{l}30.47 \\
27.59\end{array}$ & $\begin{array}{l}28.72 \\
26.01\end{array}$ & $\begin{array}{l}91.29 \\
88.35\end{array}$ & $\begin{array}{l}26.22 \\
22.98\end{array}$ & $\begin{array}{l}2.50 \\
3.03\end{array}$ & 19.38 & 651.5 \\
\hline 3000 & 73.8 & $\begin{array}{l}10 \\
20\end{array}$ & $\begin{array}{l}63.295 \\
28.766\end{array}$ & $\begin{array}{l}34.18 \\
30.78\end{array}$ & $\begin{array}{l}32.22 \\
29.02\end{array}$ & $\begin{array}{l}90.98 \\
88.23\end{array}$ & $\begin{array}{l}29.31 \\
25.60\end{array}$ & $\begin{array}{l}2.91 \\
3.42\end{array}$ & 22.19 & 721.5 \\
\hline
\end{tabular}

(cal $\mathrm{d}^{-1}$ ) in relation to body size (dry-tissue weight), at the 2 different food concentrations investigated.

Regression equations for the physiological rates (cal $\mathrm{d}^{-1}$ ) in relation to body size (dry-tissue weight) have been calculated on the basis of the values presented in Table 4; they are summarized in Table 7.

Of special interest are the equations obtained for the energy disposable for growth and reproduction (= production, $\mathrm{P}$; cal $\mathrm{d}^{-1}$ ) in relation to body size (dry-tissue weight; g), at the 2 different food concentrations investigated:

$$
\begin{aligned}
& 10 \times 10^{6} \text { cells }^{-1}: \mathrm{P}=25.48 \mathrm{~W}^{0.45} \text {, } \\
& 20 \times 10^{6} \text { cells } 1^{-1}: \mathrm{P}=17.38 \mathrm{~W}^{0.35} \text {. }
\end{aligned}
$$

From these equations it is clear that the energy balance is positive at the 2 food levels studied. The gain in energy, however, decreases with increasing food concentrations; thus, higher gain in energy for 
Table 6. Ostrea chilensis. Energy ingested and its use in the different processes in relation to body size at 2 different food concentrations Dunaliella marina; $12{ }^{\circ} \mathrm{C} ; 20 \% \mathrm{~S}$

\begin{tabular}{|c|c|c|c|c|c|c|c|c|c|c|c|}
\hline $\begin{array}{c}\text { Dry } \\
\text { tissue } \\
\text { weight } \\
\text { (mg) }\end{array}$ & $\begin{array}{c}\text { Body size } \\
\text { Shell } \\
\text { length } \\
(\mathrm{mm})\end{array}$ & $\begin{array}{l}\text { Calories } \\
\text { of } \\
\text { tissues } \\
\text { (cal) }\end{array}$ & $\begin{array}{l}\text { Energy } \\
\text { Ash-free } \\
\text { dry wt } \\
\left(\mathrm{mg} \mathrm{d}^{-1}\right)\end{array}$ & $\begin{array}{l}\text { Calories } \\
\left(\mathrm{cal} \mathrm{d}^{-1}\right)\end{array}$ & $\begin{array}{c}\text { Energy } \\
\text { assimi- } \\
\text { lated } \\
\left(\mathrm{cal} \mathrm{d}^{-1}\right)\end{array}$ & $\begin{array}{l}\text { Energy } \\
\text { lost in } \\
\text { faeces }\end{array}$ & $\begin{array}{l}\text { Energy } \\
\text { used in } \\
\text { respira- } \\
\text { tion } \\
\left(\mathrm{cal} \mathrm{d}^{-1}\right)\end{array}$ & $\begin{array}{l}\text { Energy } \\
\text { lost in } \\
\text { excretion } \\
\left(\mathrm{cal} \mathrm{d}^{-1}\right)\end{array}$ & $\begin{array}{l}\text { Energ } \\
\text { growth }+ \\
\text { Calories } \\
\left(\text { cal d }^{-1}\right)\end{array}$ & $\begin{array}{l}\text { Jy for } \\
\text { reprod. } \\
\text { Oyster } \\
\text { dry tissue } \\
\left(\mathrm{mg} \mathrm{d}^{-1}\right)\end{array}$ & $\begin{array}{c}\text { Net growth } \\
\text { efficiency } \\
\left(\mathrm{K}_{2}\right) \\
(\%)\end{array}$ \\
\hline \multicolumn{12}{|c|}{ Food concentration: $10 \times 10^{6}$ algal cells $1^{-1}$} \\
\hline 50 & 23.7 & 268 & 2.44 & 12.14 & 11.93 & 0.21 & 5.09 & 0.43 & 6.41 & 1.20 & 53.7 \\
\hline 250 & 37.1 & 1340 & 6.73 & 33.48 & 31.92 & 1.56 & 16.76 & 1.07 & 14.09 & 2.63 & 44.1 \\
\hline 500 & 44.9 & 2681 & 10.42 & 51.84 & 48.78 & 3.06 & 27.99 & 1.57 & 19.22 & 3.58 & 39.4 \\
\hline 1000 & 54.4 & 5361 & 16.13 & 80.25 & 74.54 & 5.71 & 46.74 & 2.32 & 25.48 & 4.75 & 34.2 \\
\hline 1500 & 60.9 & 8042 & 20.82 & 103.58 & 95.47 & 8.11 & 63.10 & 2.91 & 29.46 & 5.49 & 30.9 \\
\hline 2000 & 66.0 & 10723 & 24.96 & 124.18 & 113.85 & 10.33 & 78.06 & 3.42 & 32.37 & 6.04 & 28.4 \\
\hline 2500 & 70.2 & 13403 & 28.73 & 142.93 & 130.48 & 12.45 & 92.08 & 3.87 & 34.53 & 6.44 & 26.5 \\
\hline 3000 & 73.8 & 16084 & 32.23 & 160.34 & 145.88 & 14.46 & 105.38 & 4.29 & 36.21 & 6.75 & 22.6 \\
\hline \multicolumn{12}{|c|}{ Food concentration: $20 \times 10^{6}$ algal cells $1^{-1}$} \\
\hline 50 & 23.7 & 268 & 2.49 & 12.39 & 11.28 & 1.11 & 5.09 & 0.43 & 5.76 & 1.07 & 51.1 \\
\hline 250 & 37.1 & 1340 & 6.53 & 32.49 & 29.22 & 3.27 & 16.76 & 1.07 & 11.39 & 2.12 & 39.0 \\
\hline 500 & 44.9 & 2681 & 9.90 & 49.25 & 44.06 & 5.19 & 27.99 & 1.57 & 14.50 & 2.70 & 32.9 \\
\hline 1000 & 54.4 & 5361 & 15.01 & 74.67 & 66.44 & 8.23 & 46.74 & 2.32 & 17.38 & 3.24 & 26.2 \\
\hline 1500 & 60.9 & 8042 & 19.14 & 95.22 & 84.46 & 10.76 & 63.10 & 2.91 & 18.45 & 3.44 & 21.8 \\
\hline 2000 & 66.0 & 10723 & 22.75 & 113.18 & 100.18 & 13.00 & 78.06 & 3.42 & 18.70 & 3.49 & 18.7 \\
\hline 2500 & 70.2 & 13403 & 26.01 & 129.40 & 114.32 & 15.08 & 92.08 & 3.87 & 18.37 & 3.43 & 16.1 \\
\hline 3000 & 73.8 & 16084 & 29.02 & 144.37 & 127.38 & 16.99 & 105.38 & 4.29 & 17.71 & 3.30 & 13.9 \\
\hline
\end{tabular}

Table 7. Ostrea chilensis. Values of $a$ and $b$ calculated on the basis of Table 6 for the different processes $\left(\mathrm{cal} \mathrm{d}^{-1}\right)$ in relation to body size (dry-tissue wt; g) at 2 different food concentrations (Duniella marina; $12{ }^{\circ} \mathrm{C} ; 20 \% \mathrm{~S}$ )

\begin{tabular}{|c|c|c|c|c|}
\hline \multirow[t]{3}{*}{ Process } & \multicolumn{4}{|c|}{$\begin{array}{l}\text { Food concentration } \\
\qquad\left(\times 10^{6} \text { cells } 1^{-1}\right)\end{array}$} \\
\hline & \multicolumn{2}{|c|}{10} & \multicolumn{2}{|c|}{20} \\
\hline & a & $b$ & a & $b$ \\
\hline Energy ingested & 80.25 & 0.63 & 74.67 & 0.60 \\
\hline Energy lost in faeces & 5.71 & 1.03 & 8.23 & 0.67 \\
\hline Energy used in respiration & 46.74 & 0.74 & 46.74 & 0.74 \\
\hline Energy lost in excretion & 2.32 & 0.56 & 2.32 & 0.56 \\
\hline $\begin{array}{l}\text { Energy for growth + repro- } \\
\text { duction }\end{array}$ & $25.48^{\circ}$ & $0.45^{\circ}$ & 17.38 & 0.35 \\
\hline \multicolumn{5}{|c|}{$\begin{array}{l}\text { Range of body size restricted to: } 50 \text { to } 1500 \mathrm{mg} \\
\text { dry-tissue wt }\end{array}$} \\
\hline
\end{tabular}

growth and reproduction was obtained at the low food concentration. This result is of considerable importance in terms of aquaculture.

The energy used by each of the different physiological processes (Fig. 10) is expressed as percentage of the energy ingested in Table 8 . The table shows that high percentages of ingested energy are utilized for standard metabolism (31.9 to $45.1 \%$ ), digestion (14.7 to $17.9 \%$ ), and growth and reproduction (16.5 to $42.1 \%$ ); the energetic costs of feeding and the loss of energy due to excretion and faeces are small.

According to Table 8, the percentage of the energy

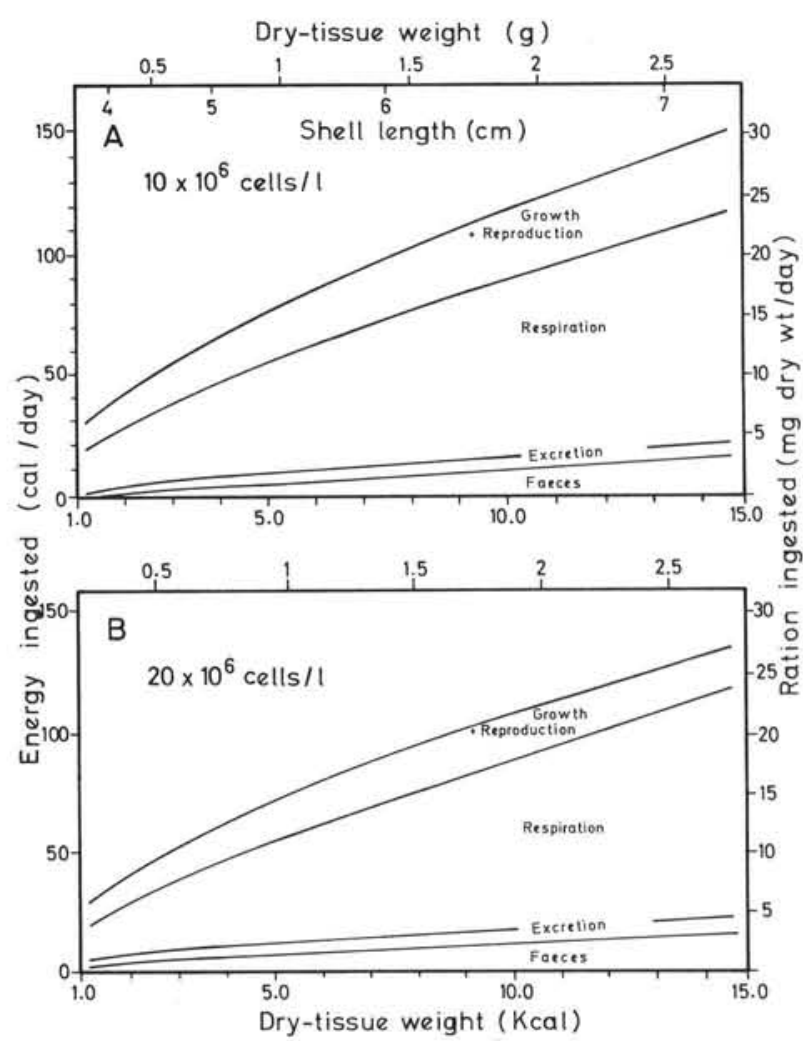

Fig. 10. Ostrea chilensis. Quantification of the energy ingested (upper line) and its ratio of distribution for different physiological processes in relation to body size (dry-tissue weight; Kcal), at 2 different Dunaliella marina concentrations $\left(12{ }^{\circ} \mathrm{C}, 20 \% \mathrm{~S}\right)$ 
Table 8. Ostrea chilensis. Energy utilization at $12{ }^{\circ} \mathrm{C}$ and $20 \% \mathrm{~S}$ in different processes in relation to body size (dry-tissue wt; g) at 2 different concentrations of Dunaliella marina, expressed as percentage of the energy ingested

\begin{tabular}{|c|c|c|c|c|c|c|}
\hline \multirow{4}{*}{$\begin{array}{l}\text { Distribution of the } \\
\text { energy ingested }\end{array}$} & \multicolumn{6}{|c|}{ Food concentrations $\left(\times 10^{6}{\left.\text { cells } ~^{-1}\right)}\right.$} \\
\hline & \multirow{2}{*}{\multicolumn{3}{|c|}{$\begin{array}{c}10 \\
\text { Dry-tissue wt }(\mathrm{g})\end{array}$}} & \multirow{2}{*}{\multicolumn{3}{|c|}{$\begin{array}{c}20 \\
\text { Dry-tissue wt (q) }\end{array}$}} \\
\hline & & & & & & \\
\hline & 0.25 & 1.00 & 2.00 & 0.25 & 1.00 & 2.00 \\
\hline Standard metabolism & 31.9 & 37.7 & 41.0 & 33.0 & 40.6 & 45.1 \\
\hline Feeding activity & 3.4 & 4.7 & 5.5 & 3.5 & 5.0 & 6.0 \\
\hline Digestion & 14.7 & 15.8 & 16.3 & 15.1 & 17.0 & 17.9 \\
\hline Faeces & 4.7 & 7.1 & 8.3 & 10.1 & 11.0 & 11.5 \\
\hline Excretion & 3.2 & 2.9 & 2.8 & 3.3 & 3.1 & 3.0 \\
\hline Growth and reproduction & 42.1 & 31.8 & 26.1 & 35.0 & 23.3 & 16.5 \\
\hline Total & 100.0 & 100.0 & 100.0 & 100.0 & 100.0 & 100.0 \\
\hline
\end{tabular}

ingested which is finally disposable for growth and reproduction depends on the high percentage of energy used for standard metabolism. Since the percentual costs of standard metabolism are much higher in large oysters than in small ones, there exists a decrease in the percentual energy available for growth and reproduction with increasing body size.

\section{Estimated growth}

The basis for calculating estimated growth is the equation for production $\left(\mathrm{P}_{i} \mathrm{Cal} \mathrm{d}^{-1}\right)$; it gives the calories disposable for growth and reproduction per day in any given size class. Conversion of calories to oyster biomass is based on the fact that the calorific content of $1 \mathrm{mg}$ of oyster biomass (dry wt) corresponds to $5361.3 \mathrm{cal}$. Furthermore, it is assumed that the conversion energy is included in the energetic costs of routine metabolism. On the basis of these considerations, the production of biomass $\left(\mathrm{PB}_{i}\right.$ gain in biomass; mg dry $w \mathrm{~d}^{-1}$ ) is given by the following equations in relation to body size (dry-tissue $\mathrm{wt}_{\text {; }}$ range: 0.05 to $1.5 \mathrm{~g}$ ) and in response to food concentration:

$$
\begin{aligned}
& 10 \times 10^{6}{\text { cells } 1^{-1}: \mathrm{PB}=4.75 \mathrm{~W}^{0.45}}^{\prime}{ }^{\prime} \times 10^{6} \text { cells } \mathrm{l}^{-1}: \mathrm{PB}=3.24 \mathrm{~W}^{0.35} .
\end{aligned}
$$

Estimated growth curves for 3 different size classes of oysters are presented in Fig. 11. These curves show that the increment in growth (dry-tissue wt) slows down with any increase in body size.

\section{Growth efficiencies $\left(K_{1}\right.$ and $\left.K_{2}\right)$}

Calculations of growth efficiencies permit the evaluation the overall effect of the culture system on growth. Hence, growth efficiencies can be used to quantify the efficiency of an aquaculture system or the suitability and adequacy of a system with respect to the species selected for cultivation.

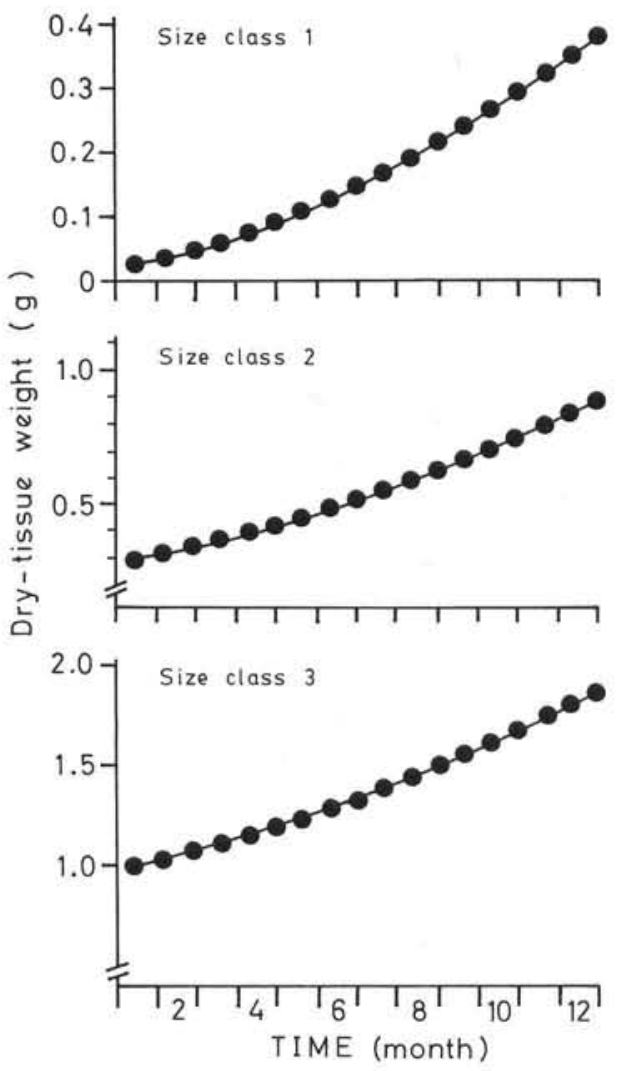

Fig. 11. Ostrea chilensis. Estimated growth in 3 different size classes (dry-tissue weight), calculated on the basis of the equation for production, $\mathrm{P}\left(12{ }^{\circ} \mathrm{C}, 20 \% \mathrm{~S}, 10 \times 10^{6}\right.$ Dunaliella marina cells $1^{-1}$ ). Calculation carried out in $20 \mathrm{~d}$ periods

An index of efficiency may be based on gross growth $\left(K_{1}\right)$ or net growth efficiency $\left(K_{2}\right)$. The difference between these 2 indices is due to the fact that the increase or decrease in body weight obtained per unit time may be expressed as percentage of the amount of organic material ingested $\left(\mathrm{K}_{1}\right)$ or as percentage of the amount of organic material assimilated $\left(K_{2}\right)$. From these definitions it is clear that $\mathrm{K}_{1}$ includes assimilation efficiency. Since assimilation efficiency is one of 
the principal variables influencing growth, the index $K_{1}$ has a more general and the index $K_{2}$ a more specific evaluation content.

The $\mathrm{K}_{1}$ - and $\mathrm{K}_{2}$-values obtained in the present study are listed in Table 6 and plotted against body size (drytissue weight) in Fig. 12. This figure reveals that gross growth and net growth efficiencies decrease drastically with increasing body size. At the low food concentration tested, $\mathrm{K}_{1}$ and $\mathrm{K}_{2}$ in small oysters $(50 \mathrm{mg}$ dry-tissue weight) are 52.8 and $53.7 \%$, respectively; in large ones $(3,000 \mathrm{mg}), 22.6$ and $24.8 \%$, respectively. At the higher food concentration, $\mathrm{K}_{1}$ and $\mathrm{K}_{2}$ are lower, especially in the larger size classes. In our experiments, the difference between gross growth and net growth efficiencies is exceptionally low due to the high assimilation efficiency obtained in oysters when fed Dunaliella marina.

The relations between body size (dry-tissue weight; g) and gross growth (GGE; \%) and net growth efficiencies $\left(\mathrm{NGE}_{i} \%\right)$ are expressed by the following equations:

gross growth efficiency:

$10 \times 10^{6}$ cells $1^{-1}:$ GGE $=30.3 \mathrm{~W}^{-0.21}$, $20 \times 10^{6}$ cells $1^{-1}:$ GGE $=20.7 \mathrm{~W}^{-0.32}$;

net growth efficiency:

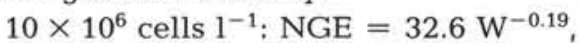
$20 \times 10^{6}$ cells $1^{-1}: \mathrm{NGE}=22.9 \mathrm{~W}^{-0.31}$.
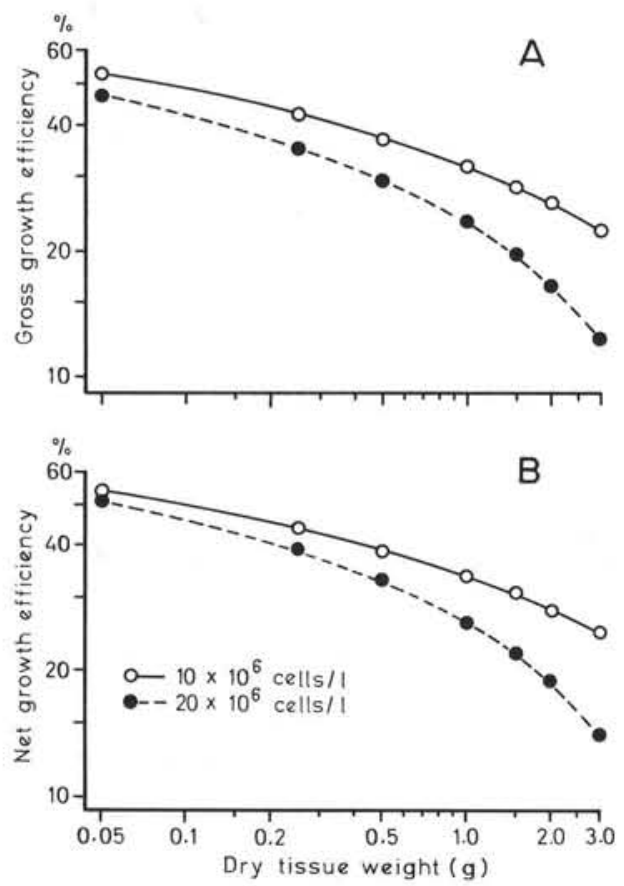

Fig. 12. Ostrea chilensis. Gross growth and net growth efficiency in relation to body weight (dry-tissue weight; g) at $10 \times 10^{6}$ and $20 \times 10^{6}$ Dunaliella marina cells $1^{-1}\left(12^{\circ} \mathrm{C}\right.$, $20 \%$ S)

\section{DISCUSSION}

Several laboratory studies have been carried out during the last decade on bivalve molluscs with the aim of determining the energy budget of Mytilus edulis (Thompson and Bayne, 1974; Riisgård and Randløv, 1981; for larvae see Sprung, 1984a, b, c, d), Mytilus chilensis (Navarro and Winter, 1982), Aulacomya ater (Griffiths and King, 1979), Choromytilus meridionalis (Griffiths, 1980), Ostrea edulis (Buxton et al., 1981), Crassostrea virginica (Langefoss and Maurer, 1975), and Crassostrea gigas (Gerdes, $1983 a, b)$.

The effects of food density on filtration and ingestion rate of filter-feeding bivalves in relation to body size have been well documented and discussed in many publications (Winter, 1969, 1970, 1973, 1977, 1978a, b; Epifanio et al., 1976; Sanina, 1976; Winter and Langton, 1976; Epifanio and Ewart, 1977; Griffiths and King, 1979; Widdows et al., 1979; Griffiths, 1980; Riisgård and Randløv, 1981; Navarro and Winter, 1982; Gerdes, 1983a). In general, filtration rate increases with increasing body size and decreases with increasing food concentration, the net effect being a function of food uptake whereby the quantity of particles filtered per unit time remains relatively constant. In this sense, the present investigation in Ostrea chilensis reconfirms the general interrelations between filtration (ingestion) rate and food density.

That these interrelations are also valid for larvae (Crassostrea gigas and Mytilus edulis) has been demonstrated by the excellent studies of Gerdes (1983a) and Sprung $(1984 a, b)$. These authors revealed that oyster and mussel larvae at different stages of development increase their ingestion rate with increasing body size, but that the amounts of food ingested are kept constant within a wide range of food densities. Such similarity in filter-feeding of adults and larvae should have been expected, since both normally live in one and the same environment.

The ability of Ostrea chilensis to regulate its filtration activity in relation to food density is of great importance for the existence of natural banks in estuarine waters, since the food concentrations used in the present study are well within the range of organic seston levels in the natural environment of this species (Toro and Winter, 1983a).

The slightly lower $a$-value obtained for the ingestion rate at $20 \times 10^{6}$ Dunaliella cells $1^{-1}$ suggests that any further increase in food concentration will have a negative effect on food intake, at least under the experimental conditions tested $\left(12^{\circ} \mathrm{C}, 20 \% \mathrm{~S}\right)$.

The present laboratory's bioenergetic studies reveal that the filter-feeding activity in the Chilean flat oyster is reduced by about $50 \%$ when compared with Mytilus 
chilensis under similar experimental conditions (Navarro and Winter, 1982). The ingested food ration of a medium-sized oyster ( $1 \mathrm{~g}$ dry-tissue wt) corresponds to about $1.7 \%$ of its dry-tissue weight per day, while in $M$. chilensis this ration varies between 3.4 and $4.1 \%$.

In Ostrea chilensis, assimilation rate is independent of food concentration and follows the same pattern of body-size dependence as described above for filtration and ingestion rates. The assimilation efficiency in $O$. chilensis turned out to be independent of body size, which is in good agreement with the results obtained in Modiolus modiolus (Winter, 1969), Mytilus edulis (Winter, 1969; Vahl, 1973; Thompson and Bayne, 1974; Widdows, 1978), and Mytilus chilensis (Navarro and Winter, 1982).

The relations between filtration rate, ingestion rate and assimilation rate in relation to food concentration are schematically outlined in Fig. 13, taking into con-

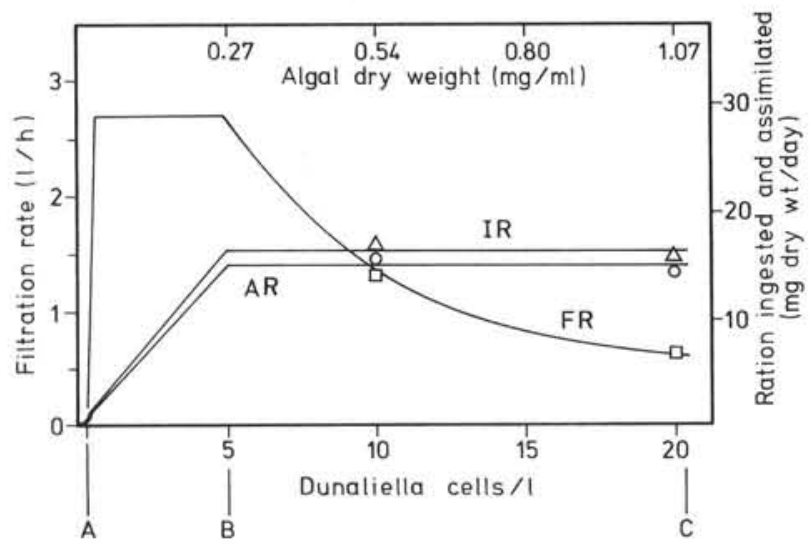

Fig. 13. Ostrea chilensis. Interrelations between filtration rate (FR), ingestion rate (IR), assimilation rate (AR), and food concentration $\left(10^{6}\right.$ cells $\left.1^{-1}\right)$

sideration the knowledge thus far available. Similar models have been presented by Winter (1978b), Navarro and Winter (1982) and Gerdes (1983a).

The relation between excretion rate and body size in Ostrea chilensis is very similar to that quantified by Bayne et al. (1976) in Mytilus californianus and by Navarro and Winter (1982) in M. chilensis. The absolute values (a-values), however, are much lower in $O$. chilensis when compared with the 2 Mytilus species, probably due to the relatively low ingestion rates in the oyster.

The relation between oxygen consumption and body size in Ostrea chilensis is in good agreement with the data reported by various authors in different lamellibranchiate bivalves (Krüger, 1960; Vahl, 1973; Thompson and Bayne, 1974; Griffiths and King, 1979; Widdows et al., 1979; Navarro and Winter, 1982). Recent studies (Gerdes, 1983b; Sprung, 1984c) confirm that oyster and mussel larvae (Crassostrea gigas, Mytilus edulis) follow the same pattern of body-size dependency as should be expected.

The costs of standard metabolism, active feeding and digestion in Ostrea chilensis and Mytilus chilensis, when expressed as percentage of total energy used in routine metabolism, are of about the same magnitude (Navarro and Winter, 1982). However, the energy used to fulfil the requirements of routine metabolism is very high in $O$. chilensis in relation to the quantity of energy ingested, i.e. about $58 \%$ (at $10 \times 10^{6}{\text { cells }{ }^{-1}}^{-1}$ ), while in $M$. chilensis these costs are not higher than $30 \%$. Future studies must decide whether this disproportion between energy ingested and energy used in routine metabolism represents a species-specific feature of $O$. chilensis or reflects a situation of environmental stress. As shown by Shumway and Koehn (1982), oxygen consumption in Crassostrea virginica is much higher at low ( 7 to $14 \% \mathrm{~S}$ ) than at high salinities $(28 \% \mathrm{~S})$, and this is even more pronounced with increasing temperatures (from $10^{\circ}$ to $30^{\circ} \mathrm{C}$ ).

From the present experiments with Ostrea chilensis it is obvious that the energy balance is positive within the range of food densities tested, i.e. from 0.54 to $1.07 \mathrm{mg}$ algal dry wt $\mathrm{l}^{-1}$. The highest scope for growth and reproduction was obtained at $0.54 \mathrm{mg}$ algal dry wt $1^{-1}$. Comparable results were obtained by Navarro and Winter (1982) in Mytilus chilensis, obtaining positive energy budgets within the range of algal food densities corresponding to $0.8 \mathrm{mg}$ and $2.14 \mathrm{mg}$ algal dry $w t l^{-1}$. In these experiments the highest scope for growth and reproduction was also obtained at the lowest food level tested.

Net growth efficiency $\left(\mathrm{K}_{2}\right)$ varies in the present experiments from $13.9 \%$ in large oysters (at the high food density tested) to $53.7 \%$ in small oysters (at the low food density tested). Thus, it decreases drastically with increasing body size (Fig. 12) and in large individuals depends to a relatively high degree on food concentration. The corresponding net growth efficiencies in Mytilus chilensis (Navarro and Winter, 1982) are considerably higher than in Ostrea chilensis. This species-specific difference is based on the low ingestion rates obtained for $O$. chilensis under the experimental conditions described above.

As a consequence of the relatively low $\mathrm{K}_{2}$-values of Ostrea chilensis, the a-values calculated for the equation of production $\left(\mathrm{P}_{i}\right.$ production of tissues and gametes) are also relatively low. Under the best food conditions tested, a 1-g oyster (dry-tissue wt) utilizes $25 \mathrm{cal} \mathrm{d}^{-1}$ for growth and reproduction; the corresponding amount is 2.3 times higher $\left(58 \mathrm{cal} \mathrm{d}^{-1}\right)$ in Mytilus chilensis.

A comparison between growth estimated in the laboratory (on the basis of the present energy budget and actual in-situ growth of the Chilean flat oyster) is 


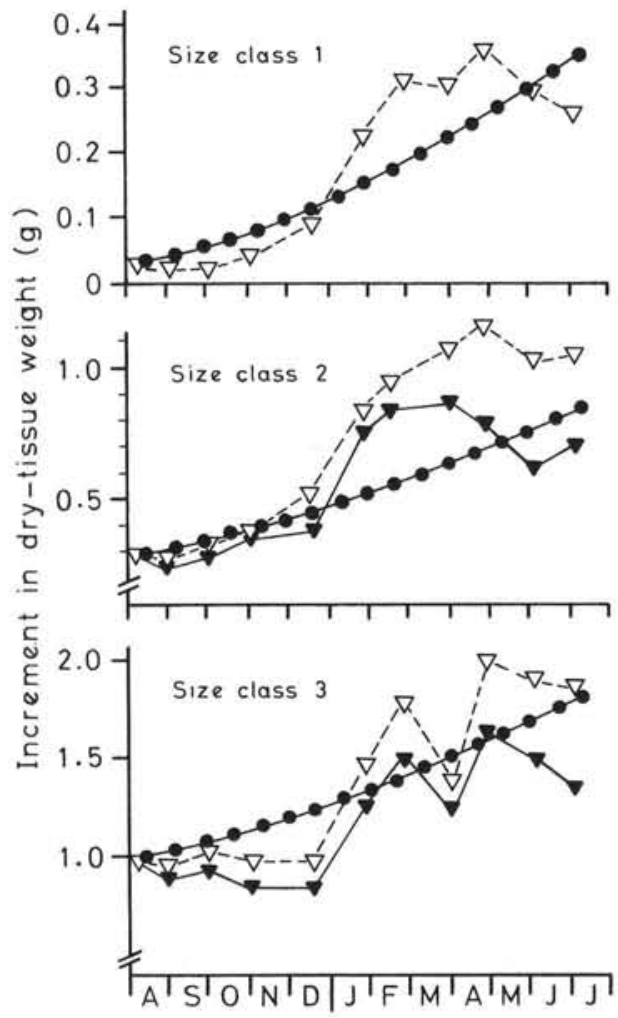

Fig. 14. Ostrea chilensis. Estimated growth in 3 different size classes, calculated on the basis of the energy budget established at $10 \times 10^{6}$ Dunaliella marina cells $1^{-1}$ (closed circles), in comparison to the actual growth determined in the estuary of the Quempillén River for oysters from the natural bank (closed triangles) and for oysters from tray cultures (open triangles)

presented in Fig. 14. In order to facilitate such comparison, the growth of 3 size classes of Ostrea chilensis was studied over $12 \mathrm{mo}$ in the estuary of the River Quempillén. For $O$. chilensis the overall gain in energy in its natural environment is practically identical to that calculated on the basis of our laboratory experiments. The much higher growth rate observed in the estuary during summer (Dec to Mar) is related to high water temperatures (about $18^{\circ} \mathrm{C}$ ), while the much lower growth rates during winter and spring, especially in Size Class 3, must be attributed to low water temperatures and to spawning and incubation. From this comparison between estimated and actual growth of Ostrea chilensis, it might be concluded that a low filter-feeding activity represents a species-specific feature of the Chilean flat oyster from estuarine populations.

Acknowledgements. This research forms part of the international project of scientific cooperation between JustusLiebig-University of Giessen (FRG) and Universidad Austral de Chile of Valdivia (Rep. Chile); it was supported by Grants S-80-3, C-80-1 and S-81-09 from the Dirección de Investigación y Desarrollo of the Universidad Austral de Chile; by the
Comisión Nacional de Investigación Científica y Tecnológica (CONICYT, Chile); by the German Foundations, Volkswagenwerk and Fritz-Thyssen; by the German Agency for Technical Cooperation (GTZ), and finally by the German Research Society (DFG). The paper forms part of the second author's thesis (Instituto de Zoología/Centro de Investigaciones Marinas, Universidad Austral de Chile). Financial support for the first author's stay in Chile was provided by the Universidad Austral de Chile and by the German Academic Exchange Service (DAAD). The present authors as well as all colleagues of the Centro de Investigaciones Marinas (CIM) are highly indebted to Professor Dr. K. J. Götting of the Institute of Zoology of the Justus-Liebig-University, Giessen (FRG), for cooperation and participation in this international aquaculture project.

\section{LITERATURE CITED}

Bayne, B. L., Bayne, C. J., Carefoot, T. C., Thompson, R. J. (1976). The physiological ecology of Mytilus californianus Conrad. I. Metabolism and energy balance. Oecologia 22: 211-228

Buxton, C. D., Newell, R. C., Field, J. G. (1981). Responsesurface analysis of the combined effects of exposure and acclimation temperatures on filtration, oxygen consumption and scope for growth in the oyster Ostrea edulis. Mar. Ecol. Prog. Ser. 6: 73-82

Conover, R. J. (1966). Assimilation of organic matter by zooplankton. Limnol. Oceanogr. 11: 338-354

Dame, R. F. (1972). The ecological energies of growth, respiration and assimilation in the intertidal American oyster Crassostrea virginica. Mar. Biol. 17: 243-250

Davis, H. C., Guillard, R. R. (1958). Relative value of ten genera of micro-organisms as foods for oyster and clam larvae. Fish. Bull. Fish Wildl. Serv. U.S. 58: 293-304

Elliot, J. M., Davison, W. (1975). Energy equivalents of oxygen consumption in animal energetics. Oecologia 19: 195-201

Epifanio, C. E., Ewart, J. (1977). Maximum ration of four diets for the oyster Crassostrea virginica Gmelin. Aquaculture 11: $13-29$

Epifanio, C. E., Logan, C. M., Turc, C. (1976). Culture of six species of bivalves in a recirculating seawater system. In: Persoone, G., Jaspers E. (ed.) Proc. 10th Eur. Symp. Mar. Biol., Ostend, Belgium, 17-23 September, 1975. Vol. 1. Universa Press, Wetteren, p. 97-108

Gerdes, D. (1983a). The Pacific oyster Crassostrea gigas. Part I. Feeding and behaviour of larvae and adults. Aquaculture 31: 195-219

Gerdes, D. (1983b). The Pacific oyster Crassostrea gigas. Part II. Oxygen consumption of larvae and adults. Aquaculture 31: 221-231

Griffiths, C. L., King, J. A. (1979). Some relationships between size, food availability and energy balance in the ribbed mussel Aulacomya ater. Mar. Biol. 51: 141-149

Griffiths, R. J. (1980). Filtration, respiration and assimilation in the black mussel Choromytilus meridionalis. Mar. Ecol. Prog. Ser. 3: 63-70

Helm, M. M. (1977). Mixed algal feeding of Ostrea edulis larvae with Isochrysis galbana and Tetraselmis suecica. J. mar. biol. Ass. U.K. 57: 1019-1029

Krüger, F. (1960). Zur Frage der Größenabhängigkeit des Sauerstoffverbrauchs von Mytilus edulis L. Helgoländer wiss. Meeresunters. 7: 125-148

Langdon, C. J., Waldock, M. J. (1981). The effect of algal and 
artificial diets on the growth and fatty acid composition of Crassostrea gigas spat. J. mar. biol. Ass. U.K. 61: 431-448

Langefoss, C. M., Maurer, D. (1975). Energy partitioning in the American oyster, Crassostrea virginica (Gmelin). Proc. natn. Shellfish. Ass. 65: 20-25

Loosanoff, V. L., Engle, J. B. (1947). Effect of different concentrations of microorganisms on the feeding of oysters. Fish. Bull. Fish Wildl. Ser. U.S. 51: 31-57

Mann, R. (1978). A comparison of morphometric, biochemical and physiological indexes of condition in marine bivalve molluscs. In: Thorp, J. H., Gibbons, J. W. (ed.) Energy and environmental stress in aquatic systems. D. O. E. Symp. Series 48, Conf. 771114. Technical Information Service, Springfield, Virginia, p. 484-497

Mann, R. (1979). The effect of temperature on growth, physiology, and gametogenesis in the manila clam Tapes philippinarum (Adams and Reeve, 1850). J. exp. mar. Biol. Ecol. 38: 121-133

Navarro, J. M., Winter, J. E. (1982). Ingestion rate, assimilation efficiency and energy balance in Mytilus chilensis in relation to body size and different algal concentrations. Mar. Biol. 67: 255-266

Riisgård, H. U., Randløv, A. (1981). Energy budgets, growth and filtration rates in Mytilus edulis L. at different algal concentrations. Mar. Biol. 61: 227-234

Ríos, C. F. (1979). Balance energético en poblaciones de Galaxias maculatus Jenyns (Salmoniformes: Galaxiidae). Medio Ambiente 4: 24-39

Sanina, L. V. (1976). Rate and intensity of filtration in some Caspian Sea bivalve molluscs. Oceanology (USSR) 15: 496-498

Shumway, S. E., Koehn, R. K. (1982). Oxygen consumption in the American oyster Crassostrea virginica. Mar. Ecol. Prog. Ser. 9: 59-68

Solórzano, L. (1969). Determination of ammonia in natural waters by the phenol-hypochlorite method. Limnol. Oceanogr. 14: 799-801

Sprung, M. (1984a). Physiological energetics of mussel larvae (Mytilus edulis L.). I. Shell growth and biomass. Mar. Ecol. Prog. Ser. 17: 283-293

Sprung, M. (1984b). Physiological energetics of mussel larvae (Mytilus edulis L.). II. Food uptake. Mar. Ecol. Prog. Ser. 17: 295-305

Sprung, M. (1984c). Physiological energetics of mussel larvae (Mytilus edulis L.). III. Respiration. Mar. Ecol. Prog. Ser. 18: $171-178$

Sprung, M. (1984d). Physiological energetics of mussel larvae (Mytilus edulis L.). IV. Efficiencies. Mar. Ecol. Prog. Ser. 18: $179-186$

Thompson, R. J., Bayne, B. L. (1974). Some relationships between growth, metabolism and food in the mussel Mytilus edulis. Mar. Biol. 27: 317-326

Toro, J. E., Winter, J. E. (1983a). Estudios en la ostricultura Quempillén, un estuario del sur de Chile. Parte I. La determinación de los factores abióticos y la cuantificación del seston como oferta alimenticia y su utilización por Ostrea chilensis. Mems Asoc. Latinoam. Acuicultura 5: 129-143

Toro, J. E., Winter, J. E. (1983b). Estudios en la ostricultura Quempillén, un estuario del sur de Chile. Parte III. Grado de utilización de la oferta alimenticia y tamaño maximo de las microalgas incluidas en el proceso de digestión de
Ostrea chilensis. Mems Asoc. Latinoam. Acuicultura 5: 161-168

Vahl, O. (1973). Pumping and oxygen consumption rates of Mytilus edulis L. of different sizes. Ophelia 12: 45-52

Walne, P. R. (1970). Studies on the food value of nineteen genera of algae to juvenile bivalves in the genera Ostrea, Crassostrea, Mercenaria and Mytilus. Fishery Invest., Lond. II 26: 1-59

Widdows, J. (1978). Combined effects of body size, food concentration and season on the physiology of Mytilus edulis. J. mar. biol. Ass. U.K. 58: 109-124

Widdows, J., Bayne, B. L. (1971). Temperature and acclimation of Mytilus edulis with reference to its energy budget. J. mar. biol. Ass. U.K. 51: 827-843

Widdows, J., Fieth, P., Worral, C. M. (1979). Relationship between seston, available food and feeding activity in the common mussel Mytilus edulis. Mar. Biol. 50: 195-207

Wilde, P. A. W. J. de (1975). Influence of temperature on behaviour, energy metabolism, and growth of Macoma balthica (L.). In: Barnes, H. (ed.) Proc, 9th Eur. Symp. Mar. Biol., Oban, Scotland, Oct. 2-8, 1974. Aberdeen University Press, Aberdeen, p. 239-256

Winter, J. E. (1969). Über den Einfluß der Nahrungskonzentration und anderer Faktoren auf Filtrierleistung und Nahrungsausnutzung der Muscheln Arctica islandica und Modiolus modiolus. Mar. Biol. 4: 87-135

Winter, J. E. (1970). Filter feeding and food utilization in Arctica islandica and Modiolus modiolus at different food concentrations. In: Steele, J. H. (ed.) Marine food chains. Oliver and Boyd, Edinburgh, p. 196-206

Winter, J. E. (1973). The filtration rate of Mytilus edulis and its dependence on algal concentrations, measured by a continuous automatic recording apparatus. Mar. Biol. 22: 317-328

Winter, J. E. (1976). Feeding experiments with Mytilus edulis L. at small laboratory scale. II. The influence of suspended silt in addition to algal suspensions on growth. In: Persoone, G., Jaspers, E. (ed.) Proc. 10th Eur. mar. Biol. Symp., Vol. 1. Universa Press, Wetteren, p. 583-600

Winter, J. E. (1977). Suspension-feeding in lamellibranchiate bivalves, with particular reference to aquaculture. Medio Ambiente 3: 48-69

Winter, J. E. (1978a). A critical review on some aspects of filter-feeding in lamellibranchiate bivalves. Haliotis, Paris 7: 71-87

Winter, J. E. (1978b). A review of the knowledge of suspension-feeding in lamellibranchiate bivalves, with special reference to artificial aquaculture systems. Aquaculture 13: $1-33$

Winter, J. E., Langton, R. W. (1976). Feeding experiments with Mytilus edulis L. at small laboratory scale. I. The influence of the total amount of food ingested and food concentration on growth. In: Persoone, G., Jaspers, E. (ed.) Proc. 10th Eur. Symp. Mar. Biol., Vol. 1. Universa Press, Wetteren, p. 565-581

Winter, J. E., Gallardo, C. S., Araya, J., Toro, J. E., Gleisner, A. (1983). Estudios en la ostricultura Quempillén, un estuario del sur de Chile. Parte II. La influencia de los factores ambientales sobre el crecimiento y los períodes de reproducción en Ostrea chilensis. Mems Asoc. Latinoam. Acuicultura 5: 145-159 